Short communication

\title{
Do white grapes really exist?
}

\author{
Panagiotis Arapitsas ${ }^{\mathrm{a}, *}$, Joana Oliveira ${ }^{\mathrm{b}}$, Fulvio Mattivi ${ }^{\text {a }}$ \\ a Department of Food Quality and Nutrition, Research and Innovation Centre, Fondazione Edmund Mach (FEM), Via E. Mach 1, 38010 San Michele all'Adige, Italy \\ b Centro de Investigação em Química, Departamento de Química e Bioquímica, Faculdade de Ciências, Universidade do Porto, Rua do Campo Alegre, 687, 4169-007 Porto, Portugal
}

\section{A R T I C L E I N F O}

\section{Article history:}

Received 11 August 2014

Accepted 3 December 2014

Available online 7 December 2014

\section{Keywords:}

Pigments

Vitis vinifera $\mathrm{L}$

Vitisins

Metabolites

Viticulture

Wine

Anthocyanins

\begin{abstract}
A B S T R A C T
Anthocyanins are natural coloured pigments representing part of the protective mechanism of many plants, including Vitis vinifera L., and they have a considerable influence on wine quality. Moreover, the presence of anthocyanins in ripe berries is used as the accepted qualitative parameter for distinguishing red from white grapes, since these pigments are known to be present only in red berries. On the other hand, pyranoanthocyanins are important pigments for the colour stability of red wines and are known to be formed after berry crushing, during vinification and wine ageing.

In this work, for the first time we provide clear evidence that the skin of international white grape cultivars (Chardonnay, Sauvignon Blanc and Riesling) contains measurable traces of anthocyanins. In addition, for the first time we report clear proofs about the presence of pyranomalvidin 3-O-glucoside (B-type vitisin) and carboxypyranomalvidin 3-O-glucoside (A-type vitisin) in fresh grapes and we quantify them.
\end{abstract}

(c) 2014 Elsevier Ltd. All rights reserved.

\section{Introduction}

Anthocyanins are natural colourants, representing the largest and the most well-known class of flavonoids and they play an important role in plant physiology. In Vitis vinifera L. grape berries, anthocyanins are found in the skin of red (as well as black and pink) grape cultivars, and their concentration depends essentially on environmental parameters, while their composition is more closely linked to genetic factors (Castellarin \& Di Gaspero, 2007; Fournier-Level, Lacombe, Le Cunff, Boursiquot, \& This, 2010; Fournier-Level et al., 2009; Pelsy, 2010). The grape synthesises anthocyanins for protection against abiotic stress, such as solar exposure and UV radiation, cold and drought, but also to attract seed dispersals. Moreover, the anthocyanin profile is of great importance from the taxonomical point of view, since it is relatively stable for each cultivar (Flamini, Mattivi, De Rosso, Arapitsas, \& Bavaresco, 2013; Mattivi, Guzzon, Vrhovsek, Stefanini, \& Velasco, 2006).

To our knowledge, anthocyanins are known to be present only in red grape cultivars, and in both analytical chemistry and biology this qualitative characteristic is used to define the difference between the two types of grape, red vs white (Castellarin \& Di Gaspero, 2007; Flamini et al., 2013; Walker et al., 2007). The concentration and the pattern of the pigments in the berry skin can also explain the attribution of “pink" vs "red" vs "black" genotypes (Pelsy, 2010). Very recently, it was reported that the reason of the pink colour wine made from the

\footnotetext{
* Corresponding author.

E-mail addresses: panagiotis.arapitsas@fmach.it, panagiotis.arapitsas@gmail.com (P. Arapitsas).
}

white $V$. vinifera L. Siria grape cultivar was the presence of anthocyanins in the grape skin and pulp (Andrea-Silva et al., 2014).

Pyranoanthocyanins such as A and B-type vitisins (Fig. 1C) on the other hand, are pigments which are formed during the vinification and ageing of wine (Arapitsas, Perenzoni, Nicolini, \& Mattivi, 2012; Arapitsas, Speri, Angeli, Perenzoni, \& Mattivi, 2014; Arapitsas et al., 2012; De Freitas \& Mateus, 2011). A-type vitisin (carboxypyranomalvidin 3-O-glucoside) is a product from the reaction between malvidin 3-Oglucoside and pyruvic acid, while B-type vitisin (pyranomalvidin 3-0-glucoside) is a product from the reaction between malvidin 3-glucoside and acetaldehyde (Bakker \& Timberlake, 1997; Fulcrand, Dos Santos, Sarni-Manchado, Cheynier, \& Favre-Bonvin, 1996). However, lately two works have demonstrated that pyranoanthocyanins in red grapes can be formed post-harvest, during the drying process (Marquez, Dueñas, Serratosa, \& Merida, 2012, 2013).

The object of this study was to examine whether white grapes contain any measurable amounts of anthocyanins and whether pyranoanthocyanins are present generally in grapes. For this purpose a new and validated and systematic ULPC-MS/MS method was used, which was shown to be sensitive enough to also detect and quantify anthocyanins in trace amounts (Arapitsas, Perenzoni, Nicolini, \& Mattivi, 2012; Ehrhardt, Arapitsas, Stefanini, Flick, \& Mattivi, 2014; Sternad Lemut, Trost, Sivilotti, Arapitsas, \& Vrhovsek, 2013).

\section{Materials and methods}

Methanol (HPLC for the extraction and LC-MS grade for the LC-MS analysis) was purchased from Fluka (Italy), and formic acid (LC-MS grade) was purchased from Sigma Aldrich (Italy). The 3-O-glucosides 


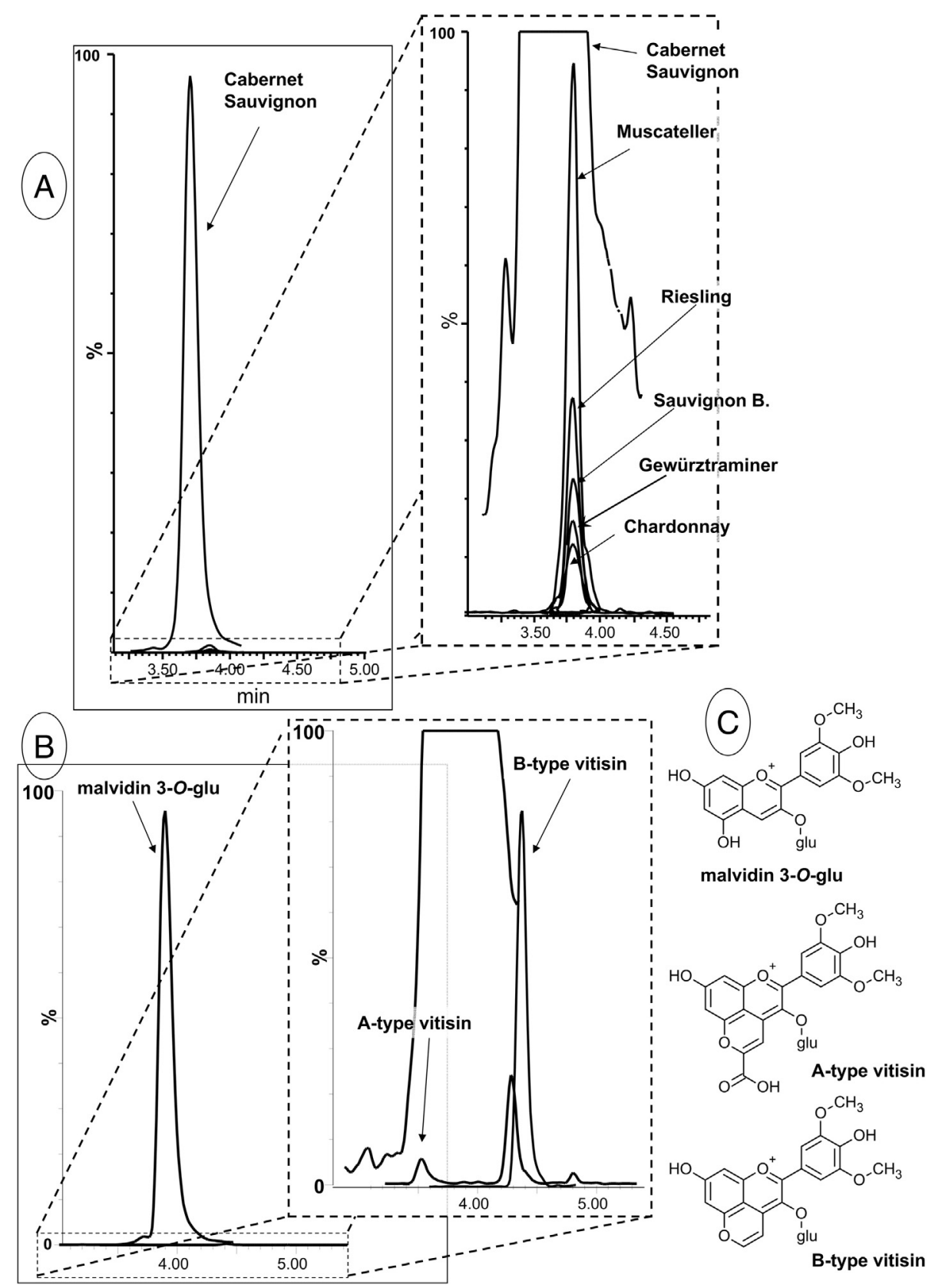

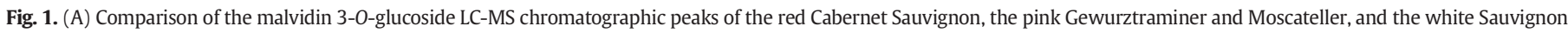

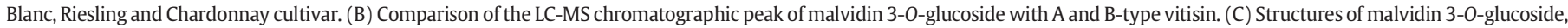
A and B-type vitisin.

and 3,5-O-diglucosides of malvidin, delphinidin, cyanidin, peonidin, petunidin and pelargonidin reference standards were of the highest purity grade available and purchased from Polyphenols Laboratories AS (Sandnes, Norway). The 3-(6"'-acetyl)-O-glucosides of peonidin and malvidin, and the 3-(6" $6^{\prime \prime}-$-coumaroyl $)-0$-glucosides malvidin, delphinidin, cyanidin, peonidin, and petunidin were isolated as previously reported (Arapitsas, Perenzoni, Nicolini, \& Mattivi, 2012; Arapitsas, Scholz, et al., 2012). A and B-type vitisins were obtained as previously described (Oliveira, De Freitas, \& Mateus, 2009; Oliveira et al., 2006). Milli-Q water was used for the chromatography and preparation of several standard solutions.

All $V$. vinifera $\mathrm{L}$. grapes were harvested from the Fondazione Edmund Mach vineyards (San Michele all'Adige, Trentino, Italy) at technological maturity and then directly frozen and stored at $-20^{\circ} \mathrm{C}$. In 2012 the red cultivars Sangiovese, Cabernet Sauvignon and Merlot, the pink cultivar Gewürztraminer, and the white cultivars Riesling and Sauvignon Blanc were sampled, while in 2011 the same cultivars were sampled, plus Chardonnay (white) and Moscateller (pink). For each sample $500 \mathrm{~g}$ was harvested, and 20 berries were randomly taken from this initial cluster three times, in order to create three biological replicates for each sample.

The 20 berries of each biological replicate were weighed and peeled; and the skins were grounded in a mortar and transferred into a $15 \mathrm{~mL}$ amber vial. The vial was filled with methanol, shaken with an orbital shaker for $30 \mathrm{~min}$ at room temperature, centrifuged for $5 \mathrm{~min}$ at $4{ }^{\circ} \mathrm{C}$ and $5000 \mathrm{rpm}$ and the liquid phase was transferred into a $50 \mathrm{~mL}$ flask. A second extraction then took place by refilling the vial up to $15 \mathrm{~mL}$, shaking and centrifuging as before, and the liquid was transferred into the same flask, which was then filled up to $50 \mathrm{~mL}$ with Milli-Q-water. Sample preparation and analysis were occurred few days after the sampling. Finally, the extract was filtered through a $0.22 \mu \mathrm{m}$ filter into a LCMS certificated vial (Arapitsas, Perenzoni, Nicolini, \& Mattivi, 2012; Arapitsas, Scholz, et al., 2012; Ehrhardt et al., 2014). 
UPLC-MS/MS analysis was carried out on a Waters Acquity UPLC system (Milford, MA), consisting of a binary pump, cooling autosampler, on-line vacuum degasser and column oven, coupled to a Waters Xevo triple-quadrupole mass spectrometer detector (TQMS; Milford, MA). The column used was a reversed phase (RP) Acquity UPLC BEH C18 $(1.7 \mu \mathrm{m}, 2.1 \times 150 \mathrm{~mm})$ column, protected with an Acquity UPLC BEH C18 precolumn $(1.7 \mu \mathrm{m}, 2.1 \times 5 \mathrm{~mm})$, used and kept at $40{ }^{\circ} \mathrm{C}$. Both LC and MS parameters are described in Ehrhardt et al. (2014) and Arapitsas, Perenzoni, Nicolini, and Mattivi (2012), Arapitsas, Scholz, et al. (2012) and reported in Supplementary material 1. A QC (quality control) pooled sample was injected after every 6 real sample injections to control instrumental performance during the analysis, as described in Ehrhardt et al. (2014). The same injection procedure was also carried out by diluting the samples of the red varieties 10 times with water, due to the signal above the linearity range. Each sample was injected twice in order to have 6 replicates/samples ( 3 biological $\times 2$ instrumental). To exclude possible sample preparation bias and injection carry over, a blank sample was also prepared according to the same protocol, without the addition of grape skins. Injections of this blank sample before and after some white, pink or red sample injections gave negative results in all cases, so carry over problems and sample preparation bias were excluded.

Data processing was carried out using Waters MassLynx version 4.1 and TargetLynx software (Waters, Milford, MA) and each compound was quantified with the calibration curve of its corresponding standard, as reported in Ehrhardt et al. (2014) and Arapitsas, Perenzoni, Nicolini, and Mattivi (2012), Arapitsas, Scholz, et al. (2012).

\section{Results and discussion}

Tables 1 and 2 show the quantification results of the anthocyanins identified in the white, red and pink grape samples analysed in this study. Due to the large differences in concentration (Fig. 1A), in red cultivars the amounts were expressed in $\mathrm{mg} / \mathrm{kg}$ of berries (Table 2 ), while in white and pink cultivars they were expressed in $\mu \mathrm{g} / \mathrm{kg}$ of berries (Table 1). Variability, expressed in \% CV, was based on 6 measurements ( $3 \times 2$ biological $\times$ instrumental) and as expected was below $20 \%$ in most cases, apart from few exceptions where the concentrations were very low (Tables 1 and 2). The analyte concentration variability of the QC sample injections was in all cases below $10 \% \mathrm{CV}$, which proved that the instrument was performing well during the analysis.

In all the cultivars and for all the compounds, it was clear that the quantities were higher for 2011 than 2012. This can be explained by the differences in the weather in the two years, as September 2012 (harvest month) was a little colder (mean value of $18^{\circ} \mathrm{C}$ ) as compared to September 2011 (mean value of $20^{\circ} \mathrm{C}$ ), and there were 16 days with rain $>0.2 \mathrm{~mm}$ in 2012 and 7 in 2011 (http://meteogardolo.altervista. $\mathrm{org} /$ ). As a result of the very rainy weather it was not possible to collect $100 \%$ healthy Chardonnay and Moscateller grapes in 2012. The accumulation of anthocyanins in the grape skin generally starts after veraison and gradually increases throughout ripening until maturity (Ribéreau-Gayon, et al., 2000), so the last stages of maturity are the most important. Since anthocyanins are part of the protection mechanism of the plant against solar exposure and UV radiation, the samples harvested in the sunnier September 2011 showed a higher concentration of pigments, as expected for an area with a relatively cool climate such as Trentino. The higher accumulation of acetylated anthocyanins (acetyl and p-coumaroyl) as compared to anthocyanin simple glucosides in years with more sunlight is also typical (Bucchetti, Matthews, Falginella, Peterlunger, \& Castellarin, 2011; Castellarin \& Di Gaspero, 2007; Flamini et al., 2013).

Although it is generally believed that white grapes do not contain anthocyanins, it is clear from Table 1 that this widely accepted statement is not true. All three white cultivars analysed in this study (Sauvignon Blanc, Riesling and Chardonnay) were able to synthesise and accumulate red pigments, in concentrations 5000-60,000 times lower as compared to red cultivars and 10-100 times lower as compared to pink cultivars (Fig. 1A). The conventional HPLC-DAD methods used in grape anthocyanin analysis are not sensitive enough to detect pigments at the level of a few $\mu \mathrm{g} / \mathrm{kg}$ grapes. However, a modern UPLC-MS/MS instrument, characterised by a higher number of chromatographic theoretical plates and a higher sensitivity detector (triple quadruple MS), is also able to detect and quantify traces of anthocyanins. Probably, the MRM modality/ tool of the triple quadruple MS has the major impact in this direction by increasing notably the signal/noise ratio. For Sauvignon Blanc and Riesling, where it was possible to compare the two years, it was evident how much the climate can also influence the concentration and profile of pigments in white cultivars. Apart from cyanidin 3-O-glucoside, all the other anthocyanins were close to or below the limit of detection for the rainy 2012 sample, while it was possible to measure all the five anthocyanin monoglucosides in the sunny 2011 samples. Indeed, the concentration of total anthocyanins in Sauvignon Blanc and Riesling was 8 times higher in 2011 as compared to 2012 and only in 2011 was it possible to detect acylated anthocyanins (acetyl and $p$-coumaroyl).

According to the literature (Boss, Davies, \& Robinson, 1996a,1996b) all the genes of the flavonoid pathway are present both in white and red grape berries, including a UDP glucose-flavonoid 3-O-glucosyl transferase (UFGT), which is involved in the last step of anthocyanin synthesis. However, UFGT was expressed only in red skinned grapes. Walker et al. (2007) found that two very similar regulatory genes, VvMYBA1 and VvMYBA2, which could activate anthocyanin biosynthesis, were not transcribed in white skin berries. Castellarin and Di Gaspero (2007) confirm the absence of UFGT in white cultivars and that the same gene was down regulated in pink cultivars as compared to red skinned varieties. To conclude, it appears that the anthocyanin content in the berry is controlled by a cluster of MYB-type transcription factor genes-thus not limited to the MYBA locus-whose activity is reported to explain the qualitative distinction between red and white cultivars, as well as the

Table 1

Anthocyanin concentration in white and pink varieties expressed in $\mu \mathrm{g} / \mathrm{kg}$ berries.

\begin{tabular}{|c|c|c|c|c|c|c|c|c|}
\hline & \multicolumn{2}{|c|}{ Sauvignon Blanc } & \multicolumn{2}{|l|}{$\underline{\text { Riesling }}$} & \multicolumn{2}{|c|}{ Gewurztraminer } & \multirow{3}{*}{$\frac{\frac{\text { Chardonnay }}{2011}}{\text { ug/kg (\%CV })}$} & \multirow{3}{*}{$\frac{\text { Moscateller }}{2011} \frac{\text { ug/kg (\%CV) }}{}$} \\
\hline & 2011 & 2012 & 2011 & 2012 & 2011 & 2012 & & \\
\hline & \multicolumn{2}{|l|}{ ug/kg (\%CV) } & \multicolumn{2}{|l|}{$\mathrm{ug} / \mathrm{kg}(\% \mathrm{CV})$} & \multicolumn{2}{|l|}{$\mathrm{ug} / \mathrm{kg}(\% \mathrm{CV})$} & & \\
\hline Dp 3-glu & 1.08 (39) & nd & $5.21(22)$ & nd & $6.11(14)$ & $8.34(12)$ & $2.02(18)$ & $82.51(8)$ \\
\hline Cy 3 glc & $7.91(18)$ & $6.66(10)$ & $62.48(19)$ & $17.67(15)$ & $981.29(14)$ & $772.12(8)$ & $9.01(25)$ & $426.29(9)$ \\
\hline Pt 3-glu & $2.51(20)$ & $0.28(8)$ & $2.34(15)$ & nd & $3.98(19)$ & $0.57(56)$ & $0.94(7)$ & $33.10(10)$ \\
\hline Pn 3-glc & $8.95(26)$ & nd & $13.04(16)$ & $0.12(62)$ & $57.85(9)$ & $42.21(17)$ & $5.78(26)$ & $247.20(13)$ \\
\hline Mv 3-glu & 34.96 (17) & $0.21(8)$ & $48.96(16)$ & nd & $17.16(16)$ & nd & $15.61(20)$ & $75.32(15)$ \\
\hline Pl 3-glc & nd & nd & $1.65(7)$ & nd & $3.71(14)$ & nd & nd & $4.69(16)$ \\
\hline B-type vitisin & nd & nd & nd & nd & $0.65(14)$ & $0.18(29)$ & nd & $6.13(44)$ \\
\hline A-type vitisin & nd & nd & nd & nd & nd & nd & nd & $2.39(44)$ \\
\hline Total acylated & nd & nd & $17.14(26)$ & nd & $24.15(22)$ & $15.82(15)$ & $3.69(34)$ & $44.37(18)$ \\
\hline Total & $55.44(10)$ & $7.29(10)$ & $138.99(16)$ & $17.97(15)$ & $1094.90(13)$ & $839.24(7)$ & 37.05 (17) & $922.00(8)$ \\
\hline
\end{tabular}

Dp: delphinidin; Cy: cyanidin; Pt: petunidin; Pn: peonidin; Mv: malvidin; Pl: pelargonidin; glu: glucoside; nd: not detected. 
Table 2

Anthocyanin concentration in red berries expressed in $\mathrm{mg} / \mathrm{kg}$ of grape.

\begin{tabular}{|c|c|c|c|c|c|c|}
\hline & \multicolumn{2}{|l|}{ Sangiovese } & \multicolumn{2}{|c|}{ Cabernet Sauvignon } & \multicolumn{2}{|l|}{ Merlot } \\
\hline & 2011 & 2012 & 2011 & 2012 & 2011 & 2012 \\
\hline & \multicolumn{2}{|l|}{ mg/kg (\%CV) } & \multicolumn{2}{|l|}{$\mathrm{mg} / \mathrm{kg}(\% \mathrm{CV})$} & \multicolumn{2}{|l|}{$\mathrm{mg} / \mathrm{kg}(\% \mathrm{CV})$} \\
\hline Dp 3-glu & $142.325(16)$ & 84.507 (19) & $323.664(10)$ & $118.683(10)$ & $135.812(15)$ & $116.543(20)$ \\
\hline Cy 3 glc & $85.017(15)$ & $43.041(17)$ & 23.463 (19) & $5.071(12)$ & $26.263(17)$ & $8.584(23)$ \\
\hline Pt 3-glu & $77.391(11)$ & $48.817(13)$ & $134.140(9)$ & $33.842(6)$ & $58.784(16)$ & $35.580(13)$ \\
\hline Pn 3-glc & $66.499(11)$ & $54.577(17)$ & 129.499 (19) & $34.979(6)$ & $87.036(16)$ & $27.852(13)$ \\
\hline Mv 3-glc & $163.243(10)$ & $126.62(13)$ & $815.296(14)$ & $193.910(8)$ & $285.486(18)$ & $137.371(14)$ \\
\hline Pl 3-glc & $0.403(6)$ & $0.349(23)$ & $1.190(14)$ & $0.281(12)$ & $0.813(13)$ & $0.114(30)$ \\
\hline B-type vitisin & $0.035(16)$ & $0.003(28)$ & $0.053(6)$ & nd & $0.042(18)$ & nd \\
\hline A-type vitisin & $4.286(20)$ & $0.509(17)$ & $29.607(7)$ & $0.451(11)$ & $6.421(18)$ & nd \\
\hline Total acylated & $55.220(12)$ & $16.465(14)$ & $1607.174(7)$ & $299.997(10)$ & $882.531(14)$ & $267.493(9)$ \\
\hline Total & $594.419(11)$ & $374.888(16)$ & $3064.086(12)$ & $687.214(8)$ & $1483.188(11)$ & 593.537 (17) \\
\hline
\end{tabular}

Dp: delphinidin; Cy: cyanidin; Pt: petunidin; Pn: peonidin; Mv: malvidin; Pl: pelargonidin; glu: glucoside; nd: not detected.

continuous quantitative variation in anthocyanin level within the coloured varieties (Fournier-Level et al., 2009; Fournier-Level et al., 2010).

The apparent conflict between our results and the literature could be explained by current technological/analytical limitations and/or by the current knowledge of plant biology. However, the second reason seems more plausible since several factors are extensively underexplored. Several other MYBs are capable of modulating the biosynthesis of flavonoids to some extent (Terrier et al., 2009) and as many as 181 putative UDPglycosyltranferases (UGTs) were found in the genome of $V$. vinifera (Caputi, Malnoy, Goremykin, Nikiforova, \& Martens, 2012). Many of the UGTs from Vitis are not yet characterised on the biochemical level and due to their often reported broad substrate specificities it can't be excluded at this stage that one or the other UGT expressed in berry skin accepts anthocyanins as substrate and is therefore involved in the synthesis of trace amounts found here.

The pink grape varieties, Gewurztraminer and Moscateller, were approximately 300-1000 times less rich in anthocyanins as compared to red cultivars and their main anthocyanin was cyanidin 3-O-glucoside, and not malvidin 3-O-glucoside as in the case of the red Cabernet Sauvignon, Merlot and Sangiovese varieties (Tables 1 and 2). As expected (Castellarin \& Di Gaspero, 2007; Mattivi et al., 2006), the anthocyanin concentration in pink cultivars was between those of red and white cultivars, but the profile was closer to that of white cultivars, as cyanidin 3$O$-glucoside was the main pigment.

Pelargonidin 3-O-glucoside is an anthocyanin recently detected in grapes (Castillo-Muñoz, Fernández-González, Gómez-Alonso, GarcíaRomero, \& Hermosín-Gutiérrez, 2009) and in agreement with the literature, it was detected its presence at a very low concentration as compared to the other anthocyanins. The amount of pelargonidin 3-O-glucoside was found to be from 0.11 to $1.19 \mathrm{mg} / \mathrm{kg}$ in the red varieties and around 4 $\mu \mathrm{g} / \mathrm{kg}$ in the pink Moscateller and Gewurztraminer varieties, while among the white cultivars it was only detected in Riesling 2011 (Tables 1 and 2).

The final scope of this study was to explore the presence of pyranoanthocyanins in grapes. Both A and B-type vitisins (Fig. 1B-C) have been detected by several authors in wine and must (Arapitsas, Perenzoni, Nicolini, \& Mattivi, 2012; Arapitsas, Scholz, et al., 2012; De Freitas \& Mateus, 2011; Sternad Lemut et al., 2013). Recently the presence of these pigments has been detected in dried red grapes (Marquez et al., 2012; Marquez et al., 2013). Some indications for their presence in grapes were published few years ago (Boido, Alcalde-Eon, Carrau, Dellacassa, \& Rivas-Gonzalo, 2006; Revilla, Pérez-Magariño, González-SanJosé, \& Beltrán, 1999), but without the use of reference standards and without quantification outputs. As shown in Table 2, the concentration of B-type vitisin in red grapes was between 35 and $53 \mu \mathrm{g} / \mathrm{kg}$ in 2011 and detected only in the Sangiovese cultivar in the 2012 samples ( $3 \mu \mathrm{g} / \mathrm{kg}$ ). In pink cultivars the concentration was even lower $(0.18-6.13 \mu \mathrm{g} / \mathrm{kg})$, and it was not detected in any of the white varieties. A-type vitisin was quantified in much higher amounts in all the red varieties as compared to B-type vitisin, with concentrations of up to $3000 \mu \mathrm{g} / \mathrm{kg}$ for Cabernet Sauvignon 2011. The amounts of these two pyranoanthocyanins were much lower compared to malvidin 3-O-glucoside, which makes it very difficult to detect these pyranoanthocyanins in grapes with a conventional HPLC-DAD method (Fig. 1B, Tables 1 and 2). B-type vitisin gave two peaks with the same MRM but with different retention time (Fig. 1B), so the use of the reference standard was of great importance to identify the right metabolite and avoid false positive identifications. Moreover, analysis of the same samples with a high resolution LC-MS QTOF instrument showed that the second peak didn't correspond to the molecular formula of B-type vitisin (data not shown). One interesting point that should be underlined is that while malvidin 3-0-glucosides were between 1.3 and 4 times higher in the sunny 2011 as compared to the rainy 2012, the pyranoanthocyanin concentration was influenced much more by the climatic changes, e.g. the amount of vitisin A was upregulated 75 times in Cabernet Sauvignon 2011 as compared to 2012 (Table 2). It seems that the synthesis of pyranoanthocyanins depends much more on climatic changes than the simple glucosides of anthocyanins. According to the literature, A-type vitisin requires the presence of pyruvic acid and B-type vitisin requires acetaldehyde (Bakker \& Timberlake, 1997; Fulcrand et al., 1996). Both pyruvic acid and acetaldehyde are products of anaerobic glycolysis, so during very hot and sunny days the plant probably copes with stress by switching from aerobic to anaerobic metabolism and activating the enzymes responsible for synthesis of the above metabolites. This would be in agreement with the results reported for raisins (Marquez et al., 2012; Marquez et al., 2013). It appears that anthocyanins could be involved in the in-vivo elimination of these "stress" metabolites. It remains unclear whether this degradation of native anthocyanins is localised in the vacuoles of the berry skin, as in the case of other reactions leading to the conversion of anthocyanins (Keller \& Hrazdina, 1998).

To conclude, this study shed some light on certain new aspects of anthocyanin chemistry. We detected anthocyanins for the first time in well known international white grapes, where they were believed to be absent. We quantified the anthocyanin concentration in 3 wellknown international white cultivars (Chardonnay, Riesling and Sauvignon). We observed that the quantities and profile are highly influenced by climatic parameters and finally for the first time in grapes we detected and quantified with a systematic analytical method the formation of the pyranoanthocyanins A and B-type vitisin. These last pigments are of great importance for the stability of red wine colour, so their presence in the grape should be a significant factor. At the same time, the occurrence of anthocyanins in white grape skins is notable from the biological point of view.

\section{Acknowledgements}

Our sincere thanks go to Marco Stefanini for sampling the grapes and Stefan Martens for his useful comments. Joana Oliveira acknowledges 
FCT (Fundação para a Ciência e a Tecnologia-Praxis SFRH/BPD/65400/ 2009) of Portugal and FEDER funding SFRH/BPD/65400/2009.

\section{Appendix A. Supplementary data}

Supplementary data to this article can be found online at http://dx. doi.org/10.1016/j.foodres.2014.12.002.

\section{References}

Andrea-Silva, J., Cosme, F., Ribeiro, L. F., Moreira, A. S. P., Malheiro, A. C., Coimbra, M. A., et al (2014). Origin of the pinking phenomenon of white wines. Journal of Agricultural and Food Chemistry, 62(24), 5651-5659, http://dx.doi.org/10.1021/jf500825h.

Arapitsas, P., Perenzoni, D., Nicolini, G., \& Mattivi, F. (2012). Study of Sangiovese wines pigment profile by UHPLC-MS/MS. Journal of Agricultural and Food Chemistry, 60(42), 10461-10471, http://dx.doi.org/10.1021/jf302617e.

Arapitsas, P., Scholz, M., Vrhovsek, U., Di Blasi, S., Biondi Bartolini, A., Masuero, D., et al. (2012). A metabolomic approach to the study of wine micro-oxygenation. PLoS ONE, 7(5), e37783, http://dx.doi.org/10.1371/journal.pone.0037783.

Arapitsas, P., Speri, G., Angeli, A., Perenzoni, D., \& Mattivi, F. (2014). The influence of storage on the "chemical age" of red wines. Metabolomics, 10(5), 816-832, http://dx.doi. org/10.1007/s11306-014-0638-X.

Bakker, J., \& Timberlake, C. F. (1997). Isolation, identification, and characterization of new color-stable anthocyanins occurring in some red wines. Journal of Agricultural and Food Chemistry, 45(1), 35-43, http://dx.doi.org/10.1021/jf960252c.

Boido, E., Alcalde-Eon, C., Carrau, F., Dellacassa, E., \& Rivas-Gonzalo, J. C. (2006). Aging effect on the pigment composition and color of Vitis vinifera L. Cv. Tannat wines. Contribution of the main pigment families to wine color. Journal of Agricultural and Food Chemistry, 54(18), 6692-6704, http://dx.doi.org/10.1021/jf061240m.

Boss, P. K., Davies, C., \& Robinson, S. P. (1996a). Expression of anthocyanin biosynthesis pathway genes in red and white grapes. Plant Molecular Biology, 32(3), 565-569.

Boss, P. K., Davies, C., \& Robinson, S. P. (1996b). Anthocyanin composition and anthocyanin pathway gene expression in grapevine sports differing in berry skin colour. Australian Journal of Grape and Wine Research, 2(3), 163-170, http://dx.doi.org/10. 1111/j.1755-0238.1996.tb00104.x.

Bucchetti, B., Matthews, M. A., Falginella, L., Peterlunger, E., \& Castellarin, S. D. (2011). Effect of water deficit on Merlot grape tannins and anthocyanins across four seasons. Scientia Horticulturae, 128(3), 297-305, http://dx.doi.org/10.1016/j.scienta.2011.02. 003.

Caputi, L., Malnoy, M., Goremykin, V., Nikiforova, S., \& Martens, S. (2012). A genome-wide phylogenetic reconstruction of family 1 UDP-glycosyltransferases revealed the expansion of the family during the adaptation of plants to life on land. The Plant journal: for cell and molecular biology, 69(6), 1030-1042, http://dx.doi.org/10.1111/j. 1365-313X.2011.04853x.

Castellarin, S. D., \& Di Gaspero, G. (2007). Transcriptional control of anthocyanin biosynthetic genes in extreme phenotypes for berry pigmentation of naturally occurring grapevines. BMC Plant Biology, 7(1), 46, http://dx.doi.org/10.1186/1471-2229-7-46.

Castillo-Muñoz, N., Fernández-González, M. Gómez-Alonso, S. García-Romero, E \& Hermosín-Gutiérrez, I. (2009). Red-color related phenolic composition of Garnacha Tintorera (Vitis vinifera L.) grapes and red wines. Journal of Agricultural and Food Chemistry, 57(17), 7883-7891, http://dx.doi.org/10.1021/jf9002736.

De Freitas, V., \& Mateus, N. (2011). Formation of pyranoanthocyanins in red wines: a new and diverse class of anthocyanin derivatives. Analytical and Bioanalytical Chemistry, 401(5), 1463-1473, http://dx.doi.org/10.1007/s00216-010-4479-9.

Ehrhardt, C., Arapitsas, P., Stefanini, M., Flick, G., \& Mattivi, F. (2014). Analysis of the phenolic composition of fungus-resistant grape varieties cultivated in Italy and Germany using UHPLC-MS/MS. Journal of Mass Spectrometry, 49(9), 860-869, http://dx.doi.org/ 10.1002/jms.3440.

Flamini, R., Mattivi, F., De Rosso, M., Arapitsas, P., Bavaresco, L., \& De Rosso, M. (2013). Advanced knowledge of three important classes of grape phenolics: Anthocyanins, stilbenes and flavonols. International Journal of Molecular Sciences, 14(10), 19651-19669, http://dx.doi.org/10.3390/ijms141019651.

Fournier-Level, A., Lacombe, T., Le Cunff, L., Boursiquot, J. -M., \& This, P. (2010). Evolution of the VvMybA gene family, the major determinant of berry colour in cultivated grapevine (Vitis vinifera L.). Heredity, 104(4), 351-362, http://dx.doi.org/10.1038/ hdy.2009.148.

Fournier-Level, Alexandre, Le Cunff, L., Gomez, C., Doligez, A., Ageorges, A., Roux, C., et al. (2009). Quantitative genetic bases of anthocyanin variation in grape (Vitis vinifera $\mathrm{L}$. ssp. sativa) berry: A quantitative trait locus to quantitative trait nucleotide integrated study. Genetics, 183(3), 1127-1139, http://dx.doi.org/10.1534/genetics.109.103929.

Fulcrand, H. Dos Santos, P. -J. C. Sarni-Manchado, P. Cheynier, V \& Favre-Bonvin, J. (1996). Structure of new anthocyanin-derived wine pigments. Journal of the Chemical Society, Perkin Transactions, 1(7), 735, http://dx.doi.org/10.1039/p19960000735.

Keller, M., \& Hrazdina, G. (1998). Interaction of nitrogen availability during bloom and light intensity during veraison. II. Effects on anthocyanin and phenolic development during grape ripening. American Journal of Enology and Viticulture, 49(3), 341-349.

Marquez, A., Dueñas, M., Serratosa, M. P., \& Merida, J. (2012). Formation of vitisins and anthocyanin-flavanol adducts during red grape drying. Journal of Agricultural and Food Chemistry, 60(27), 6866-6874, http://dx.doi.org/10.1021/jf300998p.

Marquez, A., Dueñas, M., Serratosa, M. P., \& Merida, J. (2013). Identification by HPLC-MS of anthocyanin derivatives in raisins. Journal of Chemistry, 2003, http://dx.doi.org/ 10.1155/2013/274893 (Article ID 274893), 7 pages.

Mattivi, F., Guzzon, R., Vrhovsek, U., Stefanini, M., \& Velasco, R. (2006). Metabolite profiling of grape: Flavonols and anthocyanins. Journal of Agricultural and Food Chemistry, 54(20), 7692-7702, http://dx.doi.org/10.1021/jf061538c.

Oliveira, J., De Freitas, V., \& Mateus, N. (2009). A novel synthetic pathway to vitisin B compounds. Tetrahedron Letters, 50(27), 3933-3935, http://dx.doi.org/10.1016/j.tetlet. 2009.04.072.

Oliveira, J., Fernandes, V., Miranda, C., Santos-Buelga, C., Silva, A., De Freitas, V., et al. (2006). Color properties of four cyanidin-Pyruvic acid adducts. Journal of Agricultural and Food Chemistry, 54(18), 6894-6903, http://dx.doi.org/10.1021/ jf061085b.

Pelsy, F. (2010). Molecular and cellular mechanisms of diversity within grapevine varieties. Heredity, 104(4), 331-340, http://dx.doi.org/10.1038/hdy.2009.161.

Revilla, I., Pérez-Magariño, S., González-SanJosé, M., \& Beltrán, S. (1999). Identification of anthocyanin derivatives in grape skin extracts and red wines by liquid chromatography with diode array and mass spectrometric detection. Journal of Chromatography $A$, 847(1-2), 83-90, http://dx.doi.org/10.1016/S0021-9673(99)00256-3.

Ribéreau-Gayon, P., Glories, Y., Maujean, A., \& Dubourdieu, D. (2000). Handbook of Enology Volume 2. New York: John Wiley \& Sons Ltd (Chapter 6.5).

Sternad Lemut, M., Trost, K., Sivilotti, P., Arapitsas, P., \& Vrhovsek, U. (2013). Early versus late leaf removal strategies for Pinot Noir (Vitis vinifera L.): Effect on colour-related phenolics in young wines following alcoholic fermentation. Journal of the Science of Food and Agriculture, 93(15), 3670-3681, http://dx.doi.org/10.1002/jsfa.6193.

Terrier, N., Torregrosa, L., Ageorges, A., Vialet, S., Verriès, C., Cheynier, V., et al. (2009). Ectopic expression of VvMybPA2 promotes proanthocyanidin biosynthesis in grapevine and suggests additional targets in the pathway. Plant Physiology, 149(2), 1028-1041, http://dx.doi.org/10.1104/pp. 108.131862.

Walker, A. R., Lee, E., Bogs, J., McDavid, D. A. J., Thomas, M. R., \& Robinson, S. P. (2007). White grapes arose through the mutation of two similar and adjacent regulatory genes. The Plant journal: for cell and molecular biology, 49(5), 772-785, http://dx.doi. org/10.1111/j.1365-313X.2006.02997.x. 